\title{
TRADICIÓN VITICOCLA DEL VALLE DE MOQUEGUA
}

Jorge A. Gutiérrea'

\section{INTRODUCCIÓN}

Desde hace muchos años me he interesado por reconstruir ciertos aspectos de la vida social y económica del Valle de Moquegua, atraido por los trabajos de investigación realizados por los historiadores Aurelio Miró Quesada Sosa, Franklin Pease G.Y. y Juan Antonio Montenegro y Ubaldi, quienes han dedicado su talento y afecto a temas Moqueguanos.

Don Aurelio Miró Quesada, periodista, historiador y literato de singular relieve, investigando sobre el perulero Alonso de Estrada -sevillano asentado en el Valle de Moquegua que, según todos los indicios, es el elusivo poeta alabado por Don Miguel de Cervantes Saavedra, en el Canto de Caliope de la Galatea-, Io Ilamó a buscar algunas noticias sobre la vida de Moquegua de los años 15701610 , en que vivió este conocido personaje (1977).

En los últimos tiempos la información se ha acrecentado con el estudio de los archivos de Moquegua. El historiador Franklin Pease, ha destacado el material existente, especialmente los primeros libros notariales que obran en el Archivo (1981-1982). Otra de las fuentes más abundantes y más seguras ha sido hasta ahora la Noticia de la Ciudad de Santa Catalina de Guadalcázar de Moquegua, del meritisimo Juan Montenegro y Ubaldi, publicada en 1906 en el primer tomo de la Revista Histórica, a la que había que agregar los datos dispersos en el fundamental Diccionario HistóricoBiográfico del Perú, del General Manuel de Mendiburu, gran conocedor de temas moqueguanos.

Entre tanto, como simples hilos de una trama, presento aqui algunas de las noticias que me han servido en la investigación sobre la vid en el Valle de Moquegua.

\section{TRADICIÓN VITICCOLA DEL VALLE MOQUEGUANO}

Los libros notariales de Moquegua se inauguraron en Noviembre de 1587 (Pease, 1984), con el Notario Diego Dávila, escribano de su Majestad, hijo de Don Alonso de Adrada, importante vecino y hacendado del valle de Moquegua (Diego Dávila, 21 Nov. 1593); fuentes documentales de gran interés para el estudio de la Región de Moquegua a fines del siglo XVI y principios del siglo XVII.

Son valiosas las numerosas escrituras sobre la compra, venta y arriendo de tierras y viñas entre españoles, y entre éstos y los indios; del comercio de los esclavos negros e indios en la región; los conciertos de fletamiento de vino y otros productos.

Desde 1587 se plantea en los registros la confluencia de jurisdicciones distintas en la región. El valle de Moquegua estaba sometida a la Provincia de Chucuito y por ende a la Audiencia de Charcas.

Sin embargo, la población llamada Cochuna que era la parte norte del valle de Moquegua (hoy la Villa de San Augustín de Torata), dependía de la Audiencia de Lima y de la ciudad de Arequipa (Protocolo Diego de Dávila, 12-10-1593).

En este estado de cosas, es de advertir que desde los tiempos más remotos hubieron dos pueblos en el valle de Moquegua, y otro al norte del rio que baña este valle llamado pueblo de San Sebastian de Escapagua, y a la parte de Cochuna.

Los españoles, que se fueron estableciendo en diversos puntos de la sierra y del valle de Moquegua, mantuvieron y aprovecharon, como era de esperar, las costumbres indigenas y los sistemas de trabajo que encontraron. Los encomenderos pasaron además por las alternativas generales, politicas y juridicas de la institución, en la "encomienda", la que quedó frenada y limitada no sólo con la negativa de la perpetuidad, sino en la triple medida de la visita, la tasa y la sanción por el Virrey. Quienes no eran encomenderos, pero que se 
dedicaron a faenas del campo, se superpusieron a los caciques y acrecentaron el valor económico de las tierras con la introducción de nuevos cultivos (la vid, el trigo y el olivo), nuevos animales (gallinas, caballos, mulas), nuevos sistemas de labranzas o nuevos elementos mecánicos (como molinos).

Esta ampliación tan apreciable no alteró en lo esencial la vida moqueguana; al contrario, utilizó en mucho el comercio o el trueque interregional existentes.

De aquél movimiento comercial el más importante fue el derivado de las vides que, con cepas importadas de España, se multiplicaron y prosperaron en la región por la bondad del clima casi constante en el valle. Miró Quesada revisó y estudió con fervor los archivos moqueguanos recogiendo datos de interés sobre el comienzo del cultivo de vides en la región. La más importante referencia que aporta es el de la venta hecha por Pedro de Boveda a Diego de Avila, el 16 de Agosto de 1587, de 100 botijas de vino por el precio de 425 pesos. En 1596, el casi legendario Gaspar Fernández, Lugo Cabeza de Vaca erigió una ermita, en el cerro ubicado al norte de la ciudad de Moquegua, bautizado como cerro San Bernabé, en honor del patrono de las viñas. Las fiestas por San Bernabé, que se celebraron popularmente durante muchos años, se iniciaban con una misa solemne en la mañana, seguida con una procesión en la tarde hasta el cerro donde, se cantaba la antífona y se regresaba luego a la población. Entre los más antiguos hacendados con viñas, Montenegro y Ubaldi cita en primer término a Alonso Fernández de Andrada, Pedro de Guevara y, luego, entre otros a Alonso de Estrada y Vizcarra (Perulero alabado por Cervantes Saavedra en "Canto de Coliope") que tenía su hacienda en Yaravico.

El testamento de Alonso de Estrada, del 11 de Abril de 1610, habla de su heredad, con 38,000 cepas y árboles de Castilla y de la tierra; y junto a ellos botijas y lagares, calderos de cobre, pailas, peroles, cazos, espumaderas y botijas. Eran estas últimas muy importantes, porque, como iba a explicar poco después Pedro León Portocarrero, en su Descripción General del Reyno del Perú, en "los lugares donde se coge vino fazen grande, suma de botijas y tinajas de barro y las embrean para echar el vino, porque no lo echan en ninguna otra vasija". Y el General Don Manuel de Mendiburu ha aclarado que quien enseñó a labrar las primeras botijas fue el alfarero Pedro Sánchez Albo, y que las odres de cuero de chivato para guardar el vino sólo empezaron a usarse en el Siglo XVIII, embreándolas interiormente después de ser curtidos (Miro Quesada, 1982).

No siempre fue fácil el comercio del vino. En diferentes ocasiones la corona ordenó a los Virreyes que no permitieran viñas ni olivares (el otro célebre cultivo del Valle de Moquegua), para que no compitieran con los vinos y aceites españoles. Pero como iba a consignar claramente el contador Mayor Francisco López de Caravantes en su Noticia General de la Provincia del Perú, Tierra Firme y Chile, fechada en Lima en 1630, "aunque su Magestad tiene prohibido plantar viñas en estas Provincias, no se ha guardado ni se guarda"; y asi pudo continuar y crecer por tres siglos que constituyó la gran riqueza, después infortunadamente casi desaparecida de Moquegua.

El Carmelita Antonio Vásquez de Espinoza, en su Compendio y Descripción de las Indias Occidentales, precisó:

"El rio de este hermoso valle de Moquegua que divide las jurisdicciones de las audiencias de Lima y de los Charcas porque todo el valle y viña que están en la parte norte del Río que corre esteoeste, pertenece a las audiencias de Lima, y en esta parte pone el Virrey un corregidor para su buen Gobierno, y que administra justicia, cógense en esta parte más de 30,000 botijas de vino: La otra parte del Valle de la vanda del sur, donde está fundada la villa está la Iglesia del Valle su aduocación Santa Catalina donde hay algunas viñas; es de jurisdicción de la audiencia de los Charcas, en esta parte pone el Gobernador de Chucuito un teniente por ser su gobierno ..."(1628).

Antonio Alcedo y Herrera, en su Diccionario histórico geográfico de las Indias Occidentales, añade:

"...los frutos que produce Moquegua son mucho maíz que se lleva a las provincias vecinas, y vinos que por la mayor parte reducen a aguardiente para enviar a las de la Sierra, y sólo en el valle de su nombre se coge de 60,000 arrobas; también produce alguna azúcar, trigo y otras semillas..." (1786-89) 1967.

El comercio de vino hacia tierras altas constituyó indudablemente uno de los renglones más importantes de la economia del Valle, claramente establecido en los años cubiertos por el primer libro notarial. Se sabe de la existencia de viñas, importantes desde 1567, aunque el inicio de las actividades debe ser muy anterior 
dedicaron a faenas del campo, se superpusieron a los caciques y acrecentaron el valor económico de las tierras con la introducción de nuevos cultivos (la vid, el trigo y el olivo), nuevos animales (gallinas, caballos, mulas), nuevos sistemas de labranzas o nuevos elementos mecánicos (como molinos).

Esta ampliación tan apreciable no alteró en lo esencial la vida moqueguana; al contrario, utilizó en mucho el comercio o el trueque interregional existentes.

De aquél movimiento comercial el más importante fue el derivado de las vides que, con cepas importadas de España, se multiplicaron y prosperaron en la región por la bondad del clima casi constante en el valle. Miró Quesada revisó y estudió con fervor los archivos moqueguanos recogiendo datos de interés sobre el comienzo del cultivo de vides en la región. La más importante referencia que aporta es el de la venta hecha por Pedro de Boveda a Diego de Avila, el 16 de Agosto de 1587, de 100 botijas de vino por el precio de 425 pesos. En 1596, el casi legendario Gaspar Fernández, Lugo Cabeza de Vaca erigió una ermita, en el cerro ubicado al norte de la ciudad de Moquegua, bautizado como cerro San Bernabé, en honor del patrono de las viñas. Las fiestas por San Bernabé, que se celebraron popularmente durante muchos años, se iniciaban con una misa solemne en la mañana, seguida con una procesión en la tarde hasta el cerro donde, se cantaba la antífona y se regresaba luego a la población. Entre los más antiguos hacendados con viñas, Montenegro y Ubaldi cita en primer término a Alonso Fernández de Andrada, Pedro de Guevara y, luego, entre otros a Alonso de Estrada y Vizcarra (Perulero alabado por Cervantes Saavedra en "Canto de Coliope") que tenía su hacienda en Yaravico.

El testamento de Alonso de Estrada, del 11 de Abril de 1610, habla de su heredad, con 38,000 cepas y árboles de Castilla y de la tierra; y junto a ellos botijas y lagares, calderos de cobre, pailas, peroles, cazos, espumaderas y botijas. Eran estas últimas muy importantes, porque, como iba a explicar poco después Pedro León Portocarrero, en su Descripción General del Reyno del Perú, en "los lugares donde se coge vino fazen grande, suma de botijas y tinajas de barro y las embrean para echar el vino, porque no lo echan en ninguna otra vasija". Y el General Don Manuel de Mendiburu ha aclarado que quien enseñó a labrar las primeras botijas fue el alfarero Pedro Sánchez Albo, y que las odres de cuero de chivato para guardar el vino sólo empezaron a usarse en el Siglo XVIII, embreándolas interiormente después de ser curtidos (Miro Quesada, 1982).

No siempre fue fácil el comercio del vino. En diferentes ocasiones la corona ordenó a los Virreyes que no permitieran viñas ni olivares (el otro célebre cultivo del Valle de Moquegua), para que no compitieran con los vinos y aceites españoles. Pero como iba a consignar claramente el contador Mayor Francisco López de Caravantes en su Noticia General de la Provincia del Perú, Tierra Firme y Chile, fechada en Lima en 1630, "aunque su Magestad tiene prohibido plantar viñas en estas Provincias, no se ha guardado ni se guarda"; y asi pudo continuar y crecer por tres siglos que constituyó la gran riqueza, después infortunadamente casi desaparecida de Moquegua.

El Carmelita Antonio Vásquez de Espinoza, en su Compendio y Descripción de las Indias Occidentales, precisó:

"El rio de este hermoso valle de Moquegua que divide las jurisdicciones de las audiencias de Lima y de los Charcas porque todo el valle y viña que están en la parte norte del Río que corre esteoeste, pertenece a las audiencias de Lima, y en esta parte pone el Virrey un corregidor para su buen Gobierno, y que administra justicia, cógense en esta parte más de 30,000 botijas de vino: La otra parte del Valle de la vanda del sur, donde está fundada la villa está la Iglesia del Valle su aduocación Santa Catalina donde hay algunas viñas; es de jurisdicción de la audiencia de los Charcas, en esta parte pone el Gobernador de Chucuito un teniente por ser su gobierno ..."(1628).

Antonio Alcedo y Herrera, en su Diccionario histórico geográfico de las Indias Occidentales, añade:

"...los frutos que produce Moquegua son mucho maíz que se lleva a las provincias vecinas, y vinos que por la mayor parte reducen a aguardiente para enviar a las de la Sierra, y sólo en el valle de su nombre se coge de 60,000 arrobas; también produce alguna azúcar, trigo y otras semillas..." (1786-89) 1967.

El comercio de vino hacia tierras altas constituyó indudablemente uno de los renglones más importantes de la economia del Valle, claramente establecido en los años cubiertos por el primer libro notarial. Se sabe de la existencia de viñas, importantes desde 1567, aunque el inicio de las actividades debe ser muy anterior 
Juan Antonio Montenegro y Ubaldi, en la Noticia de la ciudad de Santa Catalina de Guadalcázar de Moquegua, menciona:

"Herederos o Primeros viñantes de este pueblo de Señora Santa Catalina de Moquegua. año de 1597.

Dn. Alonso de Eștrada y Vizcarra

Dn. Diego Fernández de Córdova

Dn. Diego Fernández Godines Maldonado

Dn. Alonso Fernández Adrada

Dn. Pedro Ladrón de Guevara, el Mozo

Dn. Bernabé Vélez de Córdova

Dn. Juan de Dios Ochoa

Dn. Antonio Delgado de Abriego

Dn. Maria de Sepúlveda

Dn. Diego Fernández Dávila

Dn. Pedro Cansino

\section{La Viña Escapalaque}

Dn. Nicolás Hernández
Dn. Hernán Paria

Dn. Diego Velásquez

Dn. Bernabé Rivera Villalta

Dn. Alonso de Vargas Carbajal

Dn. Andrés de Espinoza Velásquez

Dn. Diego de Ochoa

Dn. Ramón Pares

Dn. Juan de Dios Escobar

Dn. Cristóbal Pérez Cugate

Dn. Juanez de Zaconeta

Dn. Pedro Pablo

Dn. Francisco Corso

Dn. Manuel de Acosta

Dn. Diego Fernández Talavera

Dn. Juan Cansino y Bilbao.

Tales son los hacendados de viña en 1597, y tales son las familias en tiempo que esto era pueblo, las que subsistian al tiempo de la fundación de la Villa en 1625 y muchos de ellos subsisten hasta el año de 1840 años ..." (1840)

\section{REFERENCIAS BIBLIOGRÁFICAS}

MIRO QUESADA SOSA, Aurelio. 1977. Tiempos de Leer Tiempos de Escribir.

MIRO QUESADA SOSA, Aurelio. 1982. Nuevos Temas Peruanos.

PEASE G. V., Franklin. 1983. Casos y Variaciones de la Verticalidad en los Andes del Sur.

MONTENEGRO Y UBALDI, Juan. Noticia de la Ciudad de Santa
Catalina de Guadalcázar de Moquegua, en Revista Histórica.

MASUDA, Shozo. Contribuciones a los Estudios de los Andes Centrales. 1984

DAVILA, Diego Archivo Notarial de Moquegua. 1587. 